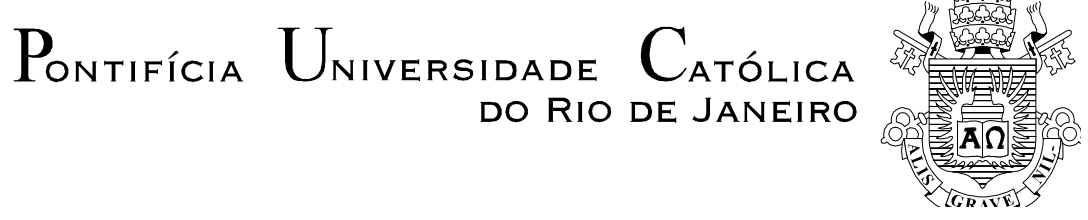

Joana Xênia Rabelo Ferreira

Fragmentárias Narrativas: A poética de Rosângela Rennó, Leila Danziger e

Caroline Valansi

\begin{abstract}
Dissertação de Mestrado
Dissertação apresentada como requisito parcial para obtenção de grau de Mestre pelo Programa de Pós-graduação em Literatura, Cultura e Contemporaneidade da PUC-Rio.
\end{abstract}

Orientadora: Profa. Ana Paula Veiga Kiffer

Rio de janeiro

Abril de 2013 


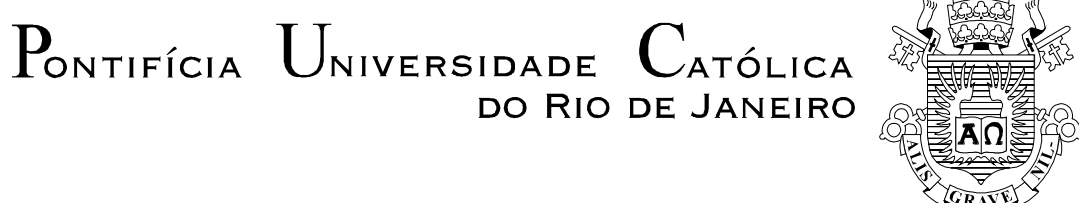

Joana Xênia Rabelo Ferreira

\section{FRAGMENTÁRIAS NARRATIVAS: A POÉTICA DE ROSÂNGELA RENNÓ, LEILA DANZIGER E CA- ROLINE VALANSI}

Dissertação apresentada como requisito parcial para obtenção do grau de Mestre pelo Programa de PósGraduação em Literatura, Cultura e Contemporaneidade do Departamento de Letras do Centro de Teologia e Ciências Humanas da PUC-Rio. Aprovada pela Comissão Examinadora abaixo assinada.

Profa. Ana Paula Veiga Kiffer

Orientadora

Departamento de Letras - PUC-Rio

Profa. Marília Rothier Cardoso

Departamento de Letras - PUC-Rio

Prof. Roberto Corrêa dos Santos UERJ

Profa. Denise Berruezo Portinari Coordenadora Setorial do Centro de Teologia

e Ciências Humanas - PUC-Rio

Rio de Janeiro, 08 de abril de 2013. 
Todos os direitos reservados. É proibida a reprodução total ou parcial do trabalho sem autorização da universidade, da autora e do orientador

\section{Joana Xênia Rabelo Ferreira}

Graduou-se em Artes pela Universidade Estadual do Rio de Janeiro - UERJ em 2009, tendo se especialização em História da Arte pela mesa instituição em 2011. Atua como curadora e professora de artes visuais.

Ficha Catalográfica

\section{Ferreira, Joana Xênia Rabelo}

Fragmentárias Narrativas: A poética de Rosangêla Rennó, Leila Danziger e Caroline Valansi / Joana Xênia Rabelo Ferreira; orientadora: Ana Paula VeigaKiffer. - Rio de Janeiro: PUC, Departamento de Letras, 2013.

$$
97 \text { f.: il (color.) ; 29,7 cm }
$$

1. Dissertação (mestrado) - Pontifícia UniversidadeCatólica do Rio de Janeiro, Departamento de Letras

Inclui referências bibliográficas.

1. Letras - Teses. 2. Narrativa. 3. Fotografia. 4. Arte contemporânea. 5. Memória. 6.Apropriação. 7. Apagamento. I. Kiffer, Ana Paula Veiga II.Pontifícia Universidade Católica do Rio de Janeiro. Departamento de Letras. III.Título. 
Aos meninos e meninas da Escola Municipal Goiás 


\section{Agradecimentos}

A minha orientadora Professora Ana Kiffer, cuja confiança e parceria foram imprescindíveis à realização desse trabalho.

Ao CNPq e à PUC-Rio, pelos auxílios concedidos, sem os quais a realização deste trabalho não seria possível.

AJosé Eduardo dos Santos e Eduardo Magalhães por tudo que vivemos.

A Marília Rothier, Eneida Leal e Rosana Kohl pelas primorosas contribuições ao longo da pesquisa.

Aos professores que participaram da Comissão examinadora.

A Ludmila Maia, Rafael Rodrigues, Ulisses Rabelo, Felipe Wircker, Natalie Araújo, Mayumi Aibe e Aline Miranda pela presença e apoio e a todos os demais amigos que sabem quem são e o que fizeram.

A todos os professores e funcionários do Departamento de Letras pelos ensinamentos e pela ajuda.

A minha mãe pelo amor incondicional

Ao meu pai pela sua filosofia mundana permeada por palavrões e gargalhadas

A minha tia Chique e sua máquina de costura, trilha sonora da minha infância 


\section{Resumo}

Ferreira, Joana Xênia Rabelo; Kiffer, Ana Paula Veiga. Fragmentárias narrativas: A poética de Rosângela Rennó, Leila Danziger e Caroline Valansi. Rio de Janeiro, 2013. 97p. Dissertação de Mestrado - Departamento de Letras, Pontifícia Universidade Católica do Rio de Janeiro.

Esta dissertação propõe algumasleiturastransversais sobre as obras "Cicatriz" de Rosângela Rennó, "Diários Públicos", de Leila Danziger e "Memórias inventadas em costuras simples" de Caroline Valansi. Nessas obras, podemos observar a contundente forma como as artistas se apropriam de fotografias, relatos, fragmentos devida, objetos e memórias de anônimos, construindo narrativas imaginárias que problematizam a separação entre "realidade" e "ficção" nas obras de arte. A idéia aqui é analisar a forma como á vida doméstica, os discursos afetivos, as narrativas individuais passam a ser objeto, foco narrativo da arte contemporânea. Pensar em como se dá esse processo de apropriação das histórias dos esquecidos, dos rostos sem nome, dos amores mal amados de amantes desimportantes, da história dos invisíveis e renegados da grande História. Entender de que maneira essas vozes - dos sem voz - são assimiladas, interpretadas, transformadas em registros, documentos, e ocupam na contemporaneidade o lugar da fala e do visível através do fazer artístico. Os trabalhos das artistas aqui tratadas fazem vir à tona (aparecer) imagens apagadas,esquecidas,condenadas à amnésia social,nos espaços artísticos institucionalizados e, por isso, forçam os limites entre arte,vida,política e estética, na medida em que "transfiguram", dotando de visibilidade espaços e imagens antes desimportantes e condenados ao apagamento.

\section{Palavras-chave}

Rosângela Rennó; Leila Danziger; Caroline Valansi; Fotografia; Narrativa; Arte contemporânea; Memória; Apropriação. 


\section{Resumen}

Ferreira, Joana Xênia Rabelo; Kiffer, Ana Paula Veiga.(Orientadora). Fragmentarias narrativas: La poética de Rosângela Rennó, Leila Danziger e Caroline Valansi. Rio de Janeiro, 2013. 97p. Tesis de MaestríaDepartamento de Letras, Pontifícia Universidade Católica do Rio de Janeiro.

Esta tesis propone lecturas tranversales acerca delas obras "Cicatriz", de Rosângela Rennó,“Diários Públicos”,de Leila Danziger, y “Memórias inventadas em costuras simples"de Caroline Valansi. En dichas obras se puede observar la forma contundente con la quelas artistas apropíanse de fotografías, relatos, fragmentos de vida, objetos y memoria de personas anónimas, construyendo narrativas imaginárias que problematizan la separación entre "realidad" y ficción en las obras de arte. La ideia es analizar la forma como la vida doméstica, los discursos afectivos, las narrativas individual pasan a ser objeto, foco narrativo del arte contemporáneo. Pensaren cómo se da el proceso de apropiación de las historias de los olvidados, de los rostros sin nombre, de los amores mal amados de amantes no importantes, de la historia de los invisibles y renegados dela grande Historia. Entender de qué manera esas vozes - de los sin voz - son asimiladas, interpretadas, transformadas en registros, documentos, y ocupan en la contemporaneidade el lugar del habla y del visible através de lhacer artístico. Los trabajos de las artistas aquí tratadas sacan a la superficie (hacen aparecer) imágenes apagadas, olvidadas, condenadas a una amnesia social, en los espacios artísticos institucionalizados y, por consiguiente, fuerzan los límites entre arte, vida, política y estética, en la medida en que "transfiguran", proveyendo de visibilidade espacios e imágenes antes no importantes e condenados al apagamiento.

\section{Palabras clave}

Rosângela Rennó; Leila Danziger; Caroline Valansi; Fotografia; Narrativa; Arte contemporâneo; Memoria; Apropiación. 
Sumário

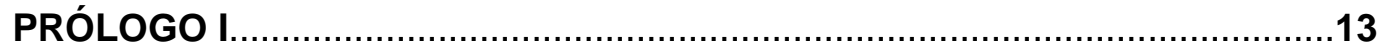

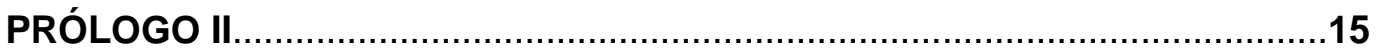

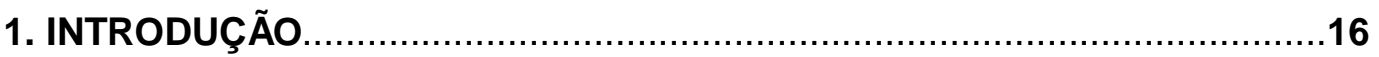

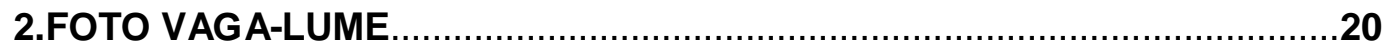

3.DIÁLOGOS

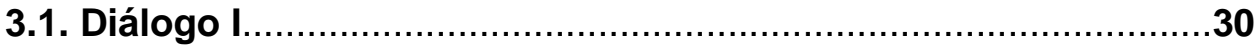

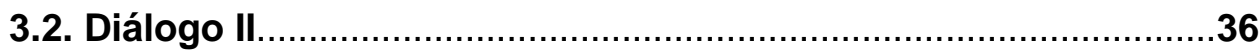

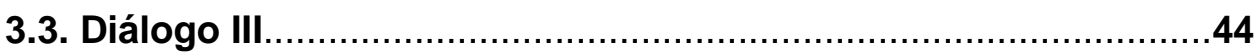

4.CAROLINE VALANSI ESUAS MEMÓRIAS INVENTADAS EM SIMPLES COSTURAS.

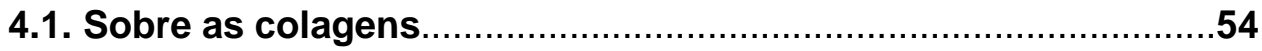

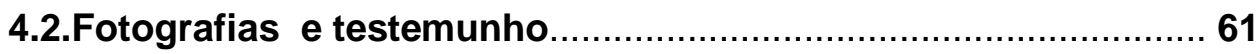

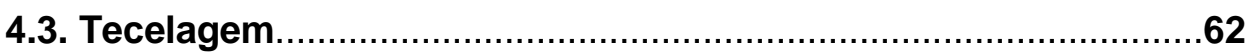

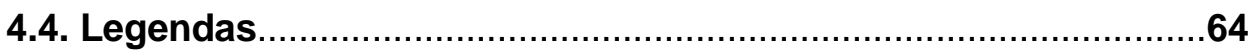

5. AS TRANSFIGURAÇÕES DE LEILA DANZIGER EM "O que desaparece, 0

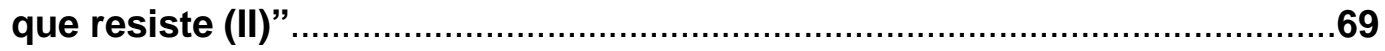

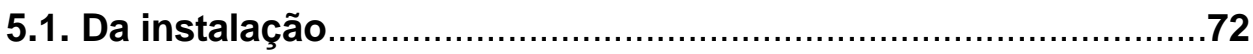

5.2. Das imagens escolhidas para resistir.......................................75

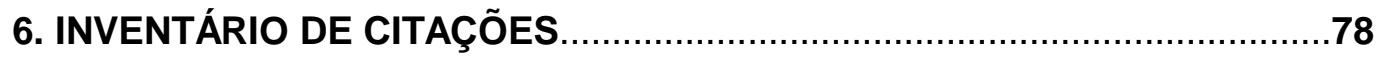

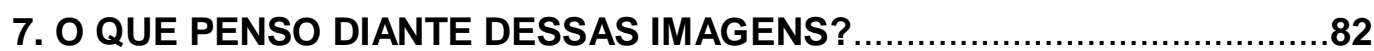

7.1. Memórias inventadas em costuras simples..............................83

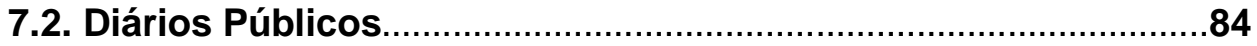

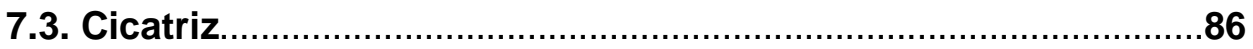




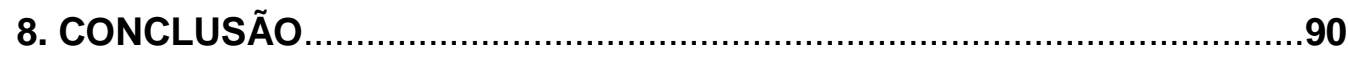

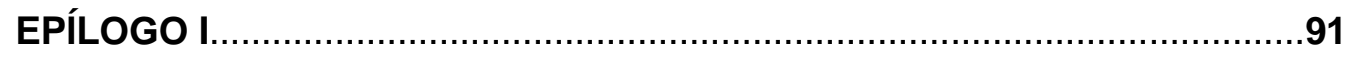

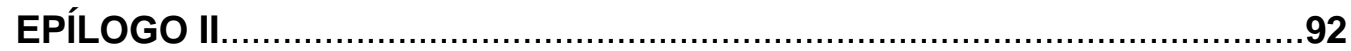

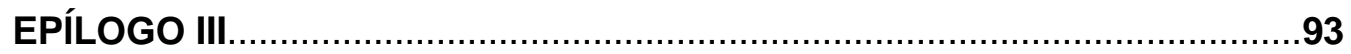

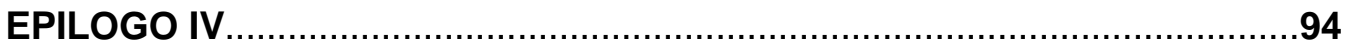

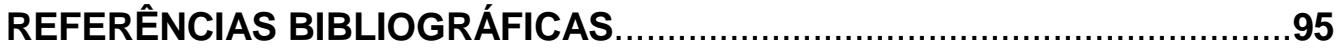




\section{Lista de figuras}

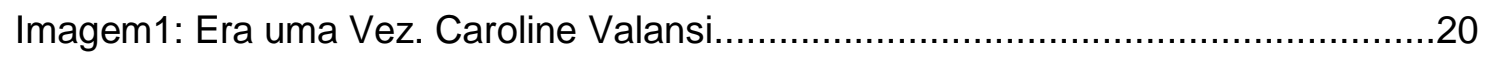

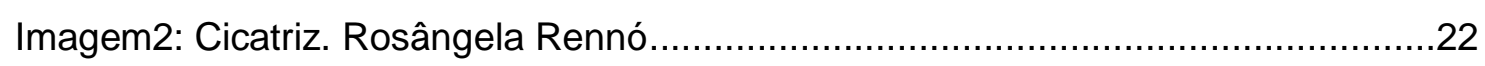

Imagem3: Diários Públicos. Leila Danziger......................................................23

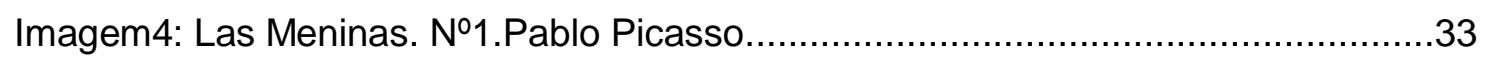

Imagem5: Las Meninas. Diego Velásquez....................................................33

Imagem6: "O Incrédulo SãoTomé”. Michelangelo de Caravaggio................................48

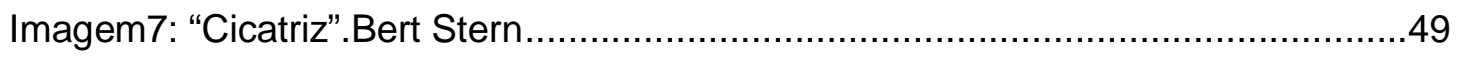

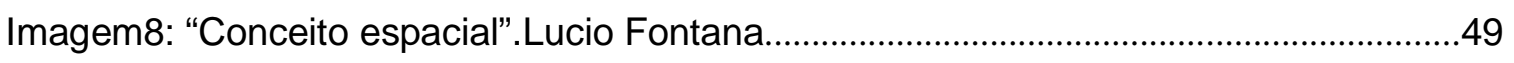

Imagem9: "Parede com incisões à La Fontana II"................................................50

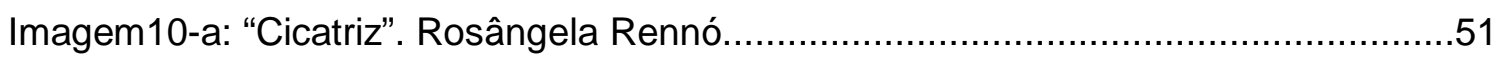

Imagem10-b: "Cicatriz”. Rosângela Rennó..........................................................

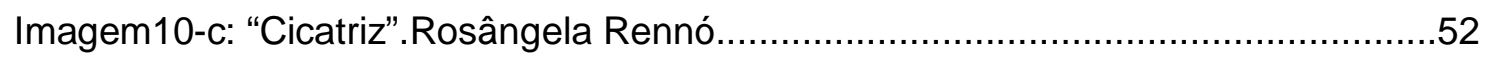

Imagem11: "Triânguloamoroso". Caroline Valansi................................................55

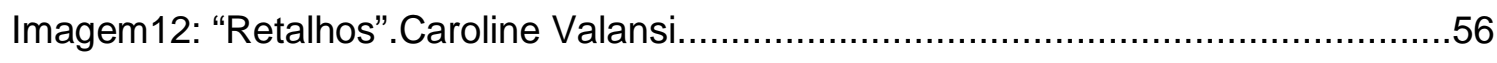

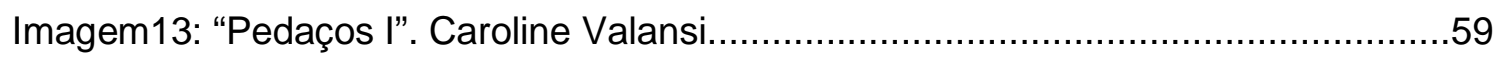

Imagem14-a: “Vera Cruz”. Rosângela Rennó..........................................................59

Imagem14-b: "Vera Cruz”. Rosângela Rennó.......................................................

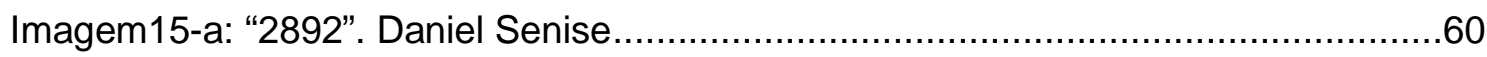

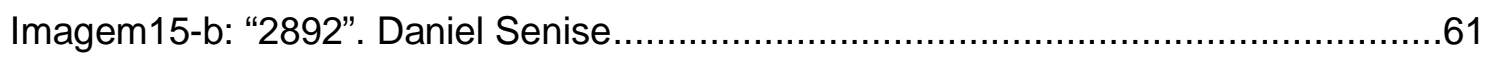

Imagem16: “Amor de Pai”. Caroline Valansi...................................................66

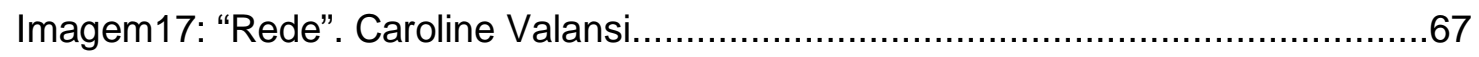


Imagem18-a:" O que desaparece, o que resiste (II)",Leila Danziger.

Imagem18-b:" O que desaparece, o que resiste (II)",Leila Danziger.........................71

Imagem18-c: "O que desaparece, o que resiste (II)",Leila Danziger........................72

Imagem19: “Diários públicos”, Leila Danziger.......................................................... 
Havia a um canto da sala um álbum de fotografias intoleráveis, alto de muitos metros e velho de infinitos minutos, em que todos se debruçavam na alegria de zombar dos mortos de sobrecasaca.

Um verme principiou a roer as sobrecasacas indiferentes e roeu as páginas, as dedicatórias e mesmo a poeira dos retratos. Só não roeu o imortal soluço de vida que rebentava que rebentava daquelas páginas.

Carlos Drummond de Andrade, Sentimento do Mundo 